\title{
Assessing Eighth-Grade Mathematics Teachers and Textbook in Embodying Thinking Levels
}

\author{
Mohammad Ahmad Alkhateeb
}

The Hashemite University, Zarqa, Jordan,mkm7879@hu.edu.jo

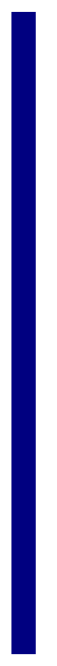

\begin{abstract}
The aim of this study was to investigate the extent of embodying thinking levels in the eighth-grade textbook and teachers' classroom questions and exams. Five teachers who teach eighth grade were chosen from schools that obtained the highest and lowest TIMSS results in Zarqa City, Jordan. Textbook content analysis, teachers' classroom observation and exam questions were assessed according to the triadic classification of thinking levels (knowledge and understanding, application and inference). The findings concerning textbooks revealed that the knowledge and understanding level obtained the highest means $(67.5 \%-81 \%)$, followed by the application level $(14.3 \%-24.1 \%)$ and questions measuring inference level (analysis 4.7\%-6.3\%), composition (0\%-1.5\%), evaluation $(0 \%)$. Questions prepared by the teachers in the exams that measured knowledge and understanding ranked first in both the highest- and lowestperformance schools. Both categories of schools achieved roughly the same rate in terms of application level. Nevertheless, the inference average rate was higher in the higher-performance schools. In general, the focus of evaluative practices, classroom questions and discussions was on the lower thinking levels, with the lowest rates being achieved by the low-performing schools.
\end{abstract}

Keywords: assessment instruments, classroom interaction, teaching practices, thinking levels, TIMSS

\section{INTRODUCTION}

Thinking is one of the most complicated processes, and has multiple ramifications and patterns. It is an organized brain activity used for problem solving, creativity in decision-making, or information analysis and the drawing of proper conclusions. Planning and development are conducted through thinking, as well as the optimal use of asking "How, When, Why" questions, which contribute to opening new perspectives for learners, and enhancing the ability to employ and obtain information from diversified sources (Rashid \& Qaisar, 2016). Teaching thinking and associated skills has become an urgent need. Accordingly, the slogans of student teaching, i.e. "How to teach" and "Teach him how to think", have gained special importance as they hold very important

Citation: Alkhateeb, M. A. (2019). Assessing Eighth-Grade Mathematics Teachers and Textbook in Embodying Thinking Levels. International Journal of Instruction, 12(1), 371-388. https://doi.org/10.29333/iji.2019.12125a 
future implications (Gencal, 2017). The learner's ability is measured by their ability to learn and their intellectual abilities to do so.

Bloom, Engelhart, Furst, Hill, and Krathwohl (1956) classified t intellectual levels to help teachers in planning educational goals and experiences, along with examinations in a gradual hierarchical form, which fits the needs of learners and individual differences. The levels are knowledge, understanding, application, analysis, composition and evaluation. Each of these levels is a prerequisite of the level next to it. Many educational research works have been interested in reviewing and studying these levels, including Anderson and Krathwohl (2001) and Krathwohl (202) and Clark (2010). They indicated that students' ability to apply learned knowledge is the best evidence of understanding and comprehension.

In this current study, the researcher followed a triadic classification for the cognitive process and related thinking levels. The first level is knowledge and understanding, which includes the low levels in Bloom's taxonomy. It is represented by defining the facts and concepts a student has stored in their memory, providing reasons for different ideas, and the ability to provide explanations for phenomena. The second level is application, which is represented by employing the acquired knowledge in new situations. The final and third level is inference, which includes higher levels in Bloom's classification (analysis, composition and evaluation). These are represented by the ability to rebuild, assemble and divide the whole into parts, detect the connectedness method of each part to another, and carry out comparisons, issue judgments and problem solving.

It is worth mentioning here that this classification of the cognitive process is the same as that applied in the TIMSS (Trends in Mathematics and Science Study) (Martin, Mullis, Foy, \& Stanco, 2012). Moreover, in the TIMSS (2015), 35\% was allocated to knowledge and understanding, 35\% to application and 30\% to inference.

With the increase in the studies concerned with thinking, due to its importance and effects in both the teaching and learning processes, the view for curricula shifted from focusing on the knowledge structure to curricula focusing on thinking and dealing with knowledge. The maths curriculum is characterized by a special characteristic, i.e. it is concerned with knowledge and employing it in the learner's life through discovery and investigations (Cathcart, Pothier, Vance, \& Bezuk, 2011). Wallace (2011) stated that educational trends assert the importance of learners' acquiring thinking levels and practices, and of teachers adopting and employing teaching methods that stimulate the learner, and increase their effectiveness by giving them the opportunity to think and investigate.

This is also emphasized by Kilday (2010), who underlined the need for including goals in the maths curriculum that focus on thinking levels, such as prediction, interference, analysis, data interpreting, thought testing and evaluation. The curriculaum should further include investigation methods and activities that allow students sufficient opportunities to initiate knowledge. Similarly, evaluation methods and instruments should include sufficient knowledge to fulfil the requirements of thinking levels. 
Accordingly, schoolbooks content analysis processes based on a number of defined criteria are a vehicle used to judge the extent to which these books include sufficient amounts of cognitive processes, and achieve suitable intellectual levels for each stage.

On the other hand, Asuman and Oylum (2007) saw that the use of modern methods and instruments in teaching provides students with a basic role in the learning process. Gruber and Boreen (2003) stressed the need to pay special attention to the thinking levels, and employ them in learning and teaching situations. This underlines the teacher's role in helping the students develop thinking levels. In this regard, Bufford (2011) maintained that the teacher's behaviour, which encourages the students' thinking, affects the self-concept of the students and their thinking processes.

Barak and Shakhman (2008) said that the influencing factors in teachers' dealing with thinking are: strategic, descriptive knowledge of the thinking concept and levels; practical use of teaching strategies concerning strengthening the higher-thinking levels; teachers' notions of their students' ability to acquire the highest possible thinking levels; and the self-perception of the teaching process toward thinking processes.

Undoubtedly, asking questions inside the classroom and homework assigned to students play a vital role in upgrading the learning process. These help the student ingrain information. The benefit is clear in asking students to carry out homework and prepare research work, whether individually or collectively, that develops cognitive levels, and in training them to be self-sufficient in terms of understanding, thinking and analysing.

In this regard, asking classroom questions is a major part of teaching levels, and one of the assessment instruments that forms an actual challenge for learners. Questions asked during the lesson period affect the formation of thinking levels (Rashid \& Qaisar, 2016). Quite recently, the wide interest in asking oral questions and their role in teaching became clear, particularly questions that emphasize developing thinking levels and problem solving (Sprague, 2008).

The homework students do, which is an expansion of the educational activities in the classroom, is a complementary part or application of what has been carried out and discussed in the classroom. Homework varies according to the lessons and desired objectives, and the differences in the students' nature and abilities. Bufford (2011) saw that the objectives of the various homework are different from each other. Some aim to approach principles or relations among thoughts, and some aim to provide opportunities for the students to think.

The assessment process and its instruments are a major element that enhances students' thinking and develops their skills. Researchers are interested in developing methods and approaches that guide and direct the assessment processes, in a manner that corresponds to the nature of the activities and thinking-provoking duties. Assessment is also a major component of the teaching process, because the quality of the assessment is down to the teacher, and their assessment results contribute to the optimization of the teaching process in terms of its objectives, means and techniques (Little, 2009). 
It is apparent from the above viewpoints that the learner's thinking levels can be developed, and a helping hand can be extended to them to take them out of their stagnation to an active state of learning. Such a shift can be achieved through using assessment instruments that encourage their thinking, and enrich their thoughts, which turns them into a researcher depending on research and discovery (Carla \& Sandra, 2014).

In the light of the trends in international tests for maths and science (TIMSS) in the years 2003, 2007, 2011 and 2015, in which Jordan participated, all indicators showed a decline of eighth-graders performance level in the different cognition areas (knowledge and understanding, application, interference), which was below the international average (National Center for Human Resources Development, 2017). Which required a study to be carried out on the focus of the maths curriculum, teaching methods and assessment instruments employed in developing these levels, in an attempt to contribute to raising the students' thinking levels.

\section{Study Problem}

The issue of thinking teaching in the educational process is of vast importance. Results of the TIMSS (2015) showed that the average number of degrees gained by Jordanian students was 386/1000, i.e. 20 lower than the 2011 round, 21 lower than the 2007 round, 18 lower than the 2003 round and 22 lower than the repetition round in 1999 (Mullis \& Martin, 2015). Such results call for deep attention, concern and investigation into the reasons for these averages, which are below the general international average of the participant countries. The researcher hopes that we shall partially identify these reasons through the focus of this study on analysing the maths schoolbook for the basic eighth grade. In addition, the study will also focus on the assessment item and the objectives it contains, which measures the thinking levels, description and analyses of the maths teachers' exams, as well as the description of the classroom discussions and analyses to detect the concentration degree in developing the students' thinking levels. As such, this study will investigate and explore the assessment instruments used by the maths teachers of the basic eighth graders in developing their students" thinking levels. However, the study problem is defined through the following questions:

1. What is the extent of concentration of the assessment items in the eighth graders' maths book on the thinking levels aspect?

2. What is the extent of concentration of the maths teachers' questions and classroom discussion on developing their students' thinking levels?

3. What is the extent of concentration of the maths teachers' exams on developing their students' thinking levels? 


\section{METHOD}

1- The study employed a descriptive qualitative approach; content analysis was used because it categorizes and classifies the forms of communication (Kim, Sefcik, \& Bradway, 2017), to interpret meaning by coding to count and draw comparison. The content analysis was for the textbook and exam questions. The instrument for classifying the assessment questions and test questions in maths was designed following a review of previous related studies, which were concerned with content analysis processes (AlHabeeb, 2014; Al-Hamami, 2015; Al-Taleeni, 2013). The instrument is a table in which the questions are classified based on cognitive areas adopted by the TIMSS. The assessment questions and exam questions that measure knowledge and understanding levels were gathered and included in the "cognition level" item. On the other hand, the exam questions that measure the direct application level and solve quantitative problems according to the rules and maths concepts classification were included within the application level. Finally, questions that measure skills concerning indirect application, analysis, composition and assessment were included within the inference level.

2- An observation method was used as a tool because it helps in "enabling researchers to learn about the activities of the people under study in the natural setting through observing and participating in those activities" (Kawulich, 2005). Researchers' observations on the teachers, to analyse the learners' teaching practices $(n=35$ observations), were utilized to monitor the classroom discussions, and record questions asked by both the teachers and students. They also included descriptions of the teachers' practices to detect their degree of concentration on their thinking levels. The researcher took into account the classroom environment where the observations were carried out, as well as recording the number of students.

\section{Population and Sample}

1: In terms of the elementary eighth graders' maths book, the analysis process focused on the assessment questions, which encompassed all the assessment questions included in the book, at the end of every lesson and unit, in addition to the exams of the maths teachers in the academic year 2016/2017. (Note: this is the adopted eighth-grade maths book for all Jordanian schools.)

2: The study population consisted of basic eighth graders' teachers in all public schools in Zarqa Governorate (Jordan), which participated in the TIMSS 2015 ( $n=13$ schools). The researcher intentionally chose two basic-stage schools for girls, whose performance average was 459.13 and 432.09 , respectively. The two schools were deemed to perform at a high level (TIMSS, 2015), since they are the closet to the medium achievement level. This level includes those students who obtained 481 and more degrees. As for the schools whose performance was below the international benchmark (i.e. 400 degrees), they were considered low-performance-level schools. As a result, the researcher chose three basic schools for boys whose performance was deemed low $(352.10,340.14$ and 335.72, respectively). The study participants comprised five teachers, who demonstrated thier readiness to cooperate with the researcher; all of them are holders of a BA degree in maths, and their years of experience ranged between 17 and 20 years. 


\section{Procedures}

1- The researcher utilized the triadic classification for the thinking levels, namely: knowledge and understanding, represented by defining the facts and concepts the students stored in their memory, and by providing reasons that lie behind the different thoughts, as well as the ability to present explanations of the phenomena; application, which is represented by employing acquired knowledge in new situations; and finally inference, which includes analysis, composition and evaluation processes. This classification is the one applied in TIMSS, 2015, as 35\% was allocated to knowledge and understanding, $35 \%$ to application and $30 \%$ to inference.

2- To analyze the assessment items included in the maths book, the researcher read both the evaluative questions at the end of each lesson and a unit of the schoolbook. Then he classified them by cognitive domain into questions that measure (knowledge and understanding, application, interference).

3- To analyse the exams, the researcher collected the exams the maths teachers prepared (three exams per teacher). Then he analysed them and classified their questions by cognitive domain into questions that measure (knowledge and understanding, application, interference).

4- The researcher and his colleague, who holds a $\mathrm{PhD}$ degree in mathematics, analysed the assessment item in the maths curriculum of the basic eighth grade, and the teachers' exams as well. Following the classification step of both the exams and the assessment questions in the maths book, the data were processed according to the percentages of all three cognitive domains (knowledge and understanding, application, inference), which measured both types of questions. The colleague provided help in realizing the reliability of the analysis results. The researcher and his colleague started their analyses separately, and after completing the analyses, the percentages were calculated to reconcile between the two analysers. In addition, the Kappa coefficient was also 00 AlZalculated to delete the effect of coincidence from the percentage of agreement between the two analysers.

5- Before starting the main observation procedures, the researcher and his colleague conducted three observations of a maths teacher in one of the participant schools in this study, to gain practice in performing classroom observations.

Different classes of teachers from the same section were attended, as the researcher and his colleague were keen to witness different subjects from the maths book being taught, and to observe teachers teaching different topics. The researcher and his colleague, individually, further wrote down all the questions asked by the teachers, and classified them into the three levels (knowledge and understanding, application, interference). In addition, they focused on the teaching methods applied by the maths teachers. The colleague was also requested to ensure reliability in the classification process, and percentages were calculated to achieve compatibility between the two analysers. 


\section{FINDINGS AND DISCUSSION}

Question 1: What is the extent of concentration of the assessment items in the eighth graders' maths book on thinking levels?

The results showed that the averages of the assessment questions of the maths book that measure the knowledge and understanding level ranged between $67.5 \%$ and $81 \%$. These percentages are higher than those of the assessment questions that measure the application level, which ranged between $14.3 \%$ and $27.1 \%$ ). Meanwhile, the average percentages of the assessment questions that measure the inference level had the lowest percentages throughout all the units in the book, with the average percentage levels being: analysis, $4.7 \%-6.3 \%$; composition, $0 \%-1.5 \%$ ); and evaluation, $0 \%$. On the other hand, the agreement ratio between the two analysers ranged between $90 \%-95 \%$, while the Kappa coefficient values ranged between $76 \%$ and $88 \%$. These results indicate a high degree of compatibility between the two analyses, as these values exceed the two acceptable compatibility limits $(80 \%)$ for the Kappa coefficient, which amounted to 0.7 , ensuring a high degree of reliability in the analysis results. Table 1 illustrates the distribution of the assessment questions in the maths book.

Table 1

Distribution of the Assessment Questions in the Maths Book of the Basic Eighth Grade, by Thinking Levels

\begin{tabular}{|c|c|c|c|c|c|c|c|c|c|c|c|}
\hline \multirow[t]{2}{*}{ Unit } & \multirow[t]{2}{*}{$\begin{array}{l}\text { No. of } \\
\text { questions }\end{array}$} & \multicolumn{2}{|c|}{$\begin{array}{l}\text { Knowledge and } \\
\text { understanding }\end{array}$} & \multicolumn{2}{|c|}{ Application } & \multicolumn{2}{|c|}{$\begin{array}{l}\text { Inference } \\
\text { analysis }\end{array}$} & \multicolumn{2}{|c|}{ composition } & \multicolumn{2}{|c|}{ evaluation } \\
\hline & & No & $\%$ & No & $\%$ & No & $\%$ & No & $\%$ & No & $\%$ \\
\hline $\begin{array}{l}\text { Two-Variable } \\
\text { Linear Equation }\end{array}$ & 37 & 25 & 67.5 & 10 & 27.1 & 2 & 5.4 & 0 & 0 & 0 & 0 \\
\hline $\begin{array}{l}\text { Geometric } \\
\text { Compositions }\end{array}$ & 21 & 17 & 81 & 3 & 14.3 & 1 & 4.7 & 0 & 0 & 0 & 0 \\
\hline Triangles & 33 & 23 & 69.8 & 8 & 24.2 & 2 & 6 & 0 & 0 & 0 & 0 \\
\hline Incarnates & 64 & 46 & 71.9 & 13 & 20.3 & 4 & 6.3 & 1 & 1.5 & 0 & 0 \\
\hline
\end{tabular}

The results of the assessment item analysis indicate an imbalance in employing thinking levels within the assessment questions. There is little focus on thinking levels that require higher mental processes, such as analysis, composition and assessment. This is in line with the results of the studies of Al-Habeeb (2014), Al-Hamami (2015) and AlTaleeni (2013), in their analyses of the maths curriculum, which showed that the concentration of the assessment questions was on the lower thinking levels.

However, these results are contrary to what was included in the general framework of the Jordanian maths curriculum, which indicated that there is a concentration on thinking levels, investigation and problem solving. There is little concentration on thinking levels that require mental operations to measure inference. This is an indication that there are certain contradictions and gaps between the curriculum development plan and the adopted books. This is also in line with the conclusions of Evnitskaya and Morton (2011) in their analysis of the contents of maths books. They found that the contents of schoolbooks do not achieve the general objectives of the maths curriculum in terms of developing thinking levels and problem solving. In this regard, the researcher suggests that the lack of schoolbooks that include sufficient amounts of 
questions that develop a higher thinking level is the reason for the low performance level in the international test, especially in inference.

Question 2: What is the extent of concentration of maths teachers' questions and classroom discussion on thinking Levels?

Before displaying the results, the following paragraphs will describe the general classroom environment where the observations in the participant schools in this study were carried out.

\section{Classroom Environment}

The lowest-performing schools have the problem of overcrowded classrooms in common, where the numbers of students range between 40 and 45 . In addition, the classrooms are somewhat narrow and noisy because of the frequent side chatter among the students, and due to the distraction of their concentration and attention to the teacher during their explanation. On the other hand, the number of classroom students in the high-achiever schools ranges between 35 and 40. The classrooms are relatively spacious, with discipline, order and quiet atmospheres, while at the same time, both lowand high-achiever schools have the same facilities and instruments, such as the use of teaching aids, blackboards.

The researcher and his colleague entered the classrooms frequently, and the students stood to welcome them. They always sat at the back, holding notebooks and pens only. At first, the students used to glance at the researchers' notebooks, trying to read what was written, but this practice soon ended after they had become accustomed to their presence.

In general, teachers started their teaching by using introductory sentences about the lesson and asking questions. The answers and frequencies varied, and only a few students paid attention to the teacher. The other group of students, who were distributed along the back rows of the classroom, displayed signs of boredom and a lack of interest, with some staring through the window or toward the researcher. They frequently nodded their heads when the teacher offered advice.

\section{Teaching Practices}

Teachers from the low-achiever schools had the largest role during the lessons, through presenting the information and explaining it in a traditional manner on the blackboard. They wrote out the lesson objectives they expected to realize throughout the lesson period (45 minutes). Then they started with a quick revision of the previous lesson, and asked the students to perform tasks to measure the level of remembering, such as:

- Write three algebraic terms

- Write the coefficients of the terms in the algebraic amounts: 7AB, 3A +5B.

Then they started explaining the lesson using the blackboard. It is worth noticing here that this method was employed in all the classroom lessons, regardless of the differences in the lessons. In addition, the teaching activities were limited to the teacher only. 
Thereafter, the conclusions were written on the blackboard so the students could copy them into their booklets. Also, it was noticeable that most of the students, most of the time, did not communicate with the teacher, due to factors that helped in dispersing their attention and due to a lack of focus, such as many students were engaged in side chatter and having fun with their classmates.

The researcher observed a style of discourse inside the classroom through which the teacher attempted to communicate an idea/information to the students. Sometimes the teacher asked a question, the students raised their hands to answer, the teacher nominated a student to answer, the student tried to answer and then the teacher commented on the answer. In other words, the dialogue began with the teacher through asking the students. Then the teacher chose the student, the chosen student answered, the teacher evaluated the answer, and so on.

Lemke (1990), Sinclair and Coulthard (1975) and Wells (1999) talked about this type of "triadic dialogue" style (Figure 1). Lemke (1990) believed that this type was the most prevalent in the classroom interaction. He further believed that this type of interaction strengthened the teacher through their power.

First: Teacher Question; parts of this question are:

1- Teacher call for bids

2- Student bid to answer

3- Teacher nomination

Second: Student Answer

Third: Teacher Evaluation, possibly followed by comments and expansion of the material by the teacher, or blaming.

\section{Figure 1. Triadic Dialogue Pattern.}

In spite of the dominance of the triadic interaction pattern in the classroom lessons, there were shifts to other patterns in the same lesson. For example, there was an initiation from a student to ask a question, which was a pattern different from the triadic dialogue, as it was an initiative of a student to start a dialogue. Lemke (1990) and Wells (1999) called it the student-teacher dialogue. Such a classroom interaction pattern is quite different from the triadic interaction in that the student asks the teacher, inquiring about something he did not know, and the teacher, in this case, answers him. However, the student might evaluate the teacher's response to them, i.e. they might accept the answer, repeat the question, nod their head in "sorrow", look at their classmates, and the like. Lemke (1990) illustrates the main hierarchy structure of this pattern as shown in the following Figure 2. 
- $\quad$ Student bid to ask

- Teacher's nomination

- Student's question

- Teacher's answer

- Teacher check-up as to whether the answer is satisfying

- Student's reaction and response.

Figure 2. Student-Teacher Dialogue.

It was noticed that the student's question to the teacher enfolded an attempt to shift from the first (triadic) dialogue pattern to the second one. Nevertheless, soon the teacher blocked the "road" before this attempt, which could be done in many ways, such as the teacher ignoring the student's question, or blaming the student for their question. Furthermore, a limited shift from the triadic pattern to the cross-discussion pattern was also noticed (Sinclair \& Coulthard, 1975), where the shift to this pattern took place when the teacher asked the student a question, and the student answered, followed by answers from one other or more students. The purpose of the comments was correcting or amending the response of the first student; most often, this comment was directed at the teacher.

The favourable triadic pattern used by the teacher, in the viewpoint of the researcher, was aimed at imposing control over the students. Moreover, the prevalent view of the schoolbook as a "sacred text" enhanced the control concepts. The observations about the authoritarian practices of the teachers, and the absence of the dialogue pattern, with its different types, dedicated the automatic learning style. Quite the contrary of what was expected from the school, as a "factor that helped the student to develop thinking levels". This was maintained in the study of Al-Hayyari (2002), that the classroom interactions are centred on the teacher with their theoretical and practical aspects. This was also emphasized in the study of Al-Mukhtar (2005), that the style focusing on the teacher is the dominant one in teaching mathematics.

In this regard, the students in the classroom built their own strategies to deal with authoritarian practices. For instance, the student forced the teacher to shift from the triadic interaction pattern to another pattern, through calling for an answer, transferring the question he was asked by the teacher to another student, showing signs of boredom, dissatisfaction and indifference, such as looking toward the window, closing the book, or the like, thereby challenging the teacher's control.

Students' dissatisfaction, boredom and indifference might be due to the differences in the intellectual structures between them and those of the teacher. In addition, it could be due to the teacher's failure to bridge the gap between both. Sometimes, this pushed the teacher to alternate the pedagogic discourse, especially when he saw signs of dissatisfaction among the distinguished students. Most often, the teacher paraphrased the concept in their own language, or used graphic representations to explain the concept. 
The influence of the distinguished student (as the teacher believed) was quite noticeable. For instance, if this student asked a question indicating non-comprehension of the concept, or made a movement indicating dissatisfaction, the teacher attempted to move his pedagogic discourse from the content text in the book. In many cases, the teacher did manage to move away from the content text; subsequently, they could not develop the intellectual structure of this student. These findings are in agreement with the study of Inamullah, Hussain, and Ud Din (2008), which underlined the need for teachers to improve their teaching practices.

As for teachers of the classes of high-achieving schools, there were mutual roles among the teachers of this category of schools and their students. In this latter case, the classroom interaction between the teacher and the students was clear through engaging the students in solving and applying a group of different examples and questions on the blackboard. Then, the teacher explained, directed and guided the student to deal with those questions. For instance:

- $\mathrm{A}$ and B are complementary angles; form two equations to find out the measurement of each, if one is 10 degrees less than the fourfold of the other.

To ensure the information was ingrained in the minds of their students, the highperforming schoolteachers provided a group of additional exercises in most of their lessons: for instance, applying what had been explained to solving a problem in the students' booklets individually during the lesson for a period of between 7 and 10 minutes. Thereafter, the teacher checked the correctness of the solution, and then they solved the problem collectively. Moreover, the students evaluated themselves in regard to these solutions and corrections, if so required, if the teacher said, "how about the answer of your classmate?" or "are there other alternatives to the solution?" The keen interest of the teachers of this category was clear in assigning the students various homework, such as additional exercises on the lesson topic. For instance:

- Laila and Ro'aa agreed to set up a plan to practise reading on a daily basis. Laila decided to read six pages in the first week; then she would add one page every week more than the previous week. On the other hand, Ro'aa decided to read two pages in the first week; then she would add two pages every week. On which week would they complete reading the same number of pages?

Other types of research questions require the students to perform research work, and write reports either individually or in groups. In addition, diversification was clear in the styles applied in presenting the information, such as working in groups to implement the educational activities of the schoolbook. The researcher believes that the nature of the role of the high-performance schoolteachers, as illustrated in the observations, contributed to motivating students to think and engage them in the teaching-learning process. Diversification in the teaching patterns contributed to putting them in situations that enable them to carry out different prediction processes - observation, analysis and results comparison - and thereafter assess them as compared with the results of the other groups. The researcher sees that this style motivated the student to use their mental levels in a positive manner, which helps in the positive interaction inside the classroom. 
This fact is asserted by Gencal (2017), as he maintained that the use of teaching models and strategies whose focus is the student enables them to deal with the different teaching situations through contemplation, thinking and problem solving, and also helps them develop thinking levels.

\section{Quality of the Questions and Discussions:}

Both the high- and low-performing schoolteachers that were observed share performance in terms of the quality of the questions asked during explanations. Both teacher groups focus on the low thinking levels, which do not exceed the knowledge and understanding and application level. Table 2 illustrates the percentage of questions that measure low thinking levels, and the percentage of questions that measure high thinking levels, asked by all the participant teachers in all the lessons observed.

Table 2

Percentages of the Questions Asked by the Teacher that Focus on Thinking Levels in all the Observed Lessons

\begin{tabular}{|c|c|c|c|c|c|c|c|c|c|c|c|c|}
\hline \multirow[t]{2}{*}{ Teacher } & \multirow{2}{*}{$\begin{array}{l}\text { Level of } \\
\text { school } \\
\text { performance }\end{array}$} & \multirow[t]{2}{*}{$\begin{array}{l}\text { No. of } \\
\text { Questions }\end{array}$} & \multicolumn{2}{|c|}{$\begin{array}{l}\text { Knowledge and } \\
\text { understanding }\end{array}$} & \multicolumn{2}{|c|}{ Application } & \multicolumn{2}{|c|}{$\begin{array}{l}\text { Inference } \\
\text { analysis }\end{array}$} & \multicolumn{2}{|c|}{ composition } & \multicolumn{2}{|c|}{ evaluation } \\
\hline & & & No & $\%$ & No & $\%$ & No & $\%$ & No & $\%$ & No & $\%$ \\
\hline 1 & High & 123 & 66 & 53.6 & 50 & 40.7 & 5 & 4.1 & 2 & 1.6 & 0 & 0 \\
\hline 2 & High & 105 & 61 & 58.1 & 38 & 36.2 & 5 & 4.7 & 1 & 1 & 0 & 0 \\
\hline 3 & Low & 54 & 35 & 64.8 & 18 & 33.3 & 1 & 1.9 & 0 & 0 & 0 & 0 \\
\hline 4 & Low & 45 & 28 & 62.2 & 17 & 37.8 & 0 & 0 & 0 & 0 & 0 & 0 \\
\hline 5 & Low & 42 & 27 & 64.3 & 15 & 35.7 & 0 & 0 & 0 & 0 & 0 & 0 \\
\hline
\end{tabular}

Table 3 shows that the highest proportion of questions were in favour of those measuring knowledge and understanding, while the proportion of questions measuring analysis was too low, at almost $4.7 \%$ only, with composition at $1.6 \%$ and evaluation at $0 \%$. Most of them were concentrated among the highest-performing schoolteachers. On the other hand, there is a clear difference in the classroom interaction level among the students of the two participant school groups. The high-performance school students' participation in performance and engagement in the teaching-learning process was higher than that of the low-performance school students. This was clear through their responses to the questions, the assignment of their opinions and the exchange of ideas between them and the teacher.

The researcher also noticed that the low-achievement schoolteachers did not give the students sufficient time to think before answering questions during discussion. They did not take into account the time that should be given to answer the question. When the researcher asked the teachers about this, they justified it by saying, "The lesson time is short, I have no time, I am supposed to complete this lesson today as per the plan." One teacher said, "I have large numbers of students, I cannot spend all the lesson time thinking about an answer." Naturally, this reduced the students' chances of reaching advanced levels in thinking skills. This conclusion is in line with that of Sulkua and Abdioglub (2015), who emphasized the necessity of giving a waiting time after asking questions, particularly questions that measure higher levels of thinking, to give the students a chance to understand the question, and retrieve their ideas about it, to draw links between them, evaluate them and come to a conclusion. 
On the other hand, both schoolteacher groups encouraged the students in most of the classroom lessons, and used stimulating phrases and words (such as "well done", "excellent", "hero", "your answer is correct), which increased their enthusiasm to participate and discuss.

The results of the observations on both groups of schoolteachers showed a vivid difference in the degree of interest of the two teacher groups in developing the thinking levels of their students, as well as a difference in the number of questions asked for discussion. Moreover, there are things in common between the two school groups, such as the use of teaching aids, and tools available in the classrooms. Nevertheless, the teachers from the high-performance schools showed a number of indicators that, one way or another, might influence the development of thinking levels among their students: for instance, diversifying their teaching practices; attention to assigning students to homework duties that contain additional questions, other than those in the content; follow-up; and writing research reports about subjects pertinent to the lesson. This is in line with the results of the study of Harrigan, and Vincenti 2004), who emphasized that using tasks based on problem solving helped in developing thinking levels among the students. This is also in line with Akyuzi (2014), who maintained that homeworks that require fact obtaining, explaining the reading material, and analysing, linking and comparing the ideas in different teaching contexts contribute to realizing better levels of thinking levels among the students.

This result is almost identical to the results from research on the quality of the classroom questions that the teachers ask, in terms of their focus on the lower levels of thinking levels, for instance Sulkua and Abdioglub (2015), Carla and Sandra (2014), Rashid and Qaisar (2016), whose results ensured that the focus of the classroom questions was on the lower thinking levels in the different teaching subjects, whether in science, maths or social studies.

However, the researcher was interested in the high-performing schoolteachers asking questions that motivate students to use thinking levels, although the rate of such questions was low, and did not exceed 6\%, as shown in Table 2. Nevertheless, this low percentage is higher than that of the questions asked by the low-performing schoolteachers, which contributed to a certain extent to reducing learning information by heart, and encouraged the students to learn and reach higher levels of thinking.

\section{Question 3: To what degree do teachers' exams include thinking levels?}

The results indicated that the knowledge and understanding level was the highest in teachers' exams in both schools, with the percentage of high-performing schools being $48.73 \%-55 \%$, whereas it was $71.93 \%, 78.1 \%$ and $79.67 \%$ in low-performing schools. The application level was $38.37 \%$ and $29.33 \%$, respectively, in the two high-performing schools, while the percentages were $25.53 \%, 20.9 \%$ and $20.67 \%$, respectively, in the low-performing schools.

With regard to inference level, which included three sublevels, the analysis sublevel in the two high-performing schools was $11.67 \%-14.47 \%$, respectively. On the other hand, these percentages in the three low-performing schools were $2.5 \%, 1 \%$ and $0 \%$. The 
second sublevel is composition, which obtained in the two higher-performing schools $1.1 \%$, while in low-performing schools it was $0 \%$. All schools in both categories obtained zero representation of the last sublevel, which is evaluation. Table 3 shows the results.

Table 3

Distribution of the Maths Test Questions by Thinking Levels

\begin{tabular}{|c|c|c|c|c|c|c|c|c|c|c|c|c|}
\hline \multirow{3}{*}{$\begin{array}{l}\text { School } \\
\text { performance }\end{array}$} & \multirow[t]{3}{*}{ Test } & \multirow{3}{*}{$\begin{array}{l}\text { No. of } \\
\text { questions }\end{array}$} & \multirow{2}{*}{\multicolumn{2}{|c|}{$\begin{array}{l}\text { Knowledge and } \\
\text { understanding }\end{array}$}} & \multirow{2}{*}{\multicolumn{2}{|c|}{ Application }} & \multicolumn{6}{|c|}{ Inference } \\
\hline & & & & & & & \multicolumn{2}{|c|}{ analysis } & \multicolumn{2}{|c|}{ composition } & \multicolumn{2}{|c|}{ evaluation } \\
\hline & & & No & $\%$ & No & $\%$ & No & $\%$ & No & $\%$ & No & $\%$ \\
\hline \multirow[t]{4}{*}{ High } & 1 & 15 & 6 & 40 & 7 & 46.6 & 2 & 13.3 & 0 & 0 & 0 & 0 \\
\hline & 2 & 17 & 9 & 52.9 & 6 & 35.2 & 2 & 11.7 & 0 & 0 & 0 & 0 \\
\hline & 3 & 30 & 16 & 53.3 & 10 & 33.3 & 3 & 10 & 1 & 3.3 & 0 & 0 \\
\hline & Average & 20.67 & 10.33 & 48.73 & 7.67 & 38.37 & 2.33 & 11.67 & 0.33 & 1.1 & 0 & 0 \\
\hline \multirow[t]{4}{*}{ High } & 1 & 16 & 9 & 56.2 & 5 & 31.2 & 2 & 12.5 & 0 & 0 & 0 & 0 \\
\hline & 2 & 17 & 10 & 58.8 & 4 & 23.5 & 3 & 17.6 & 0 & 0 & 0 & 0 \\
\hline & 3 & 30 & 15 & 50 & 10 & 33.3 & 4 & 13.3 & 1 & 3.3 & 0 & 0 \\
\hline & Average & 21 & 11.33 & 55 & 6.33 & 29.33 & 3 & 14.47 & 0.33 & 1.1 & 0 & 0 \\
\hline \multirow[t]{4}{*}{ Low } & 1 & 20 & 14 & 70 & 5 & 25 & 1 & 5 & 0 & 0 & 0 & 0 \\
\hline & 2 & 24 & 17 & 70.8 & 7 & 29.1 & 0 & 0 & 0 & 0 & 0 & 0 \\
\hline & 3 & 40 & 30 & 75 & 9 & 22.5 & 1 & 2.5 & 0 & 0 & 0 & 0 \\
\hline & Average & 28.00 & 20.33 & 71.93 & 7.00 & 25.53 & 0.67 & 2.50 & 0 & 0 & 0 & 0 \\
\hline \multirow[t]{4}{*}{ Low } & 1 & 23 & 18 & 78.3 & 5 & 21.7 & 0 & 0 & 0 & 0 & 0 & 0 \\
\hline & 2 & 20 & 17 & 85 & 3 & 15 & 0 & 0 & 0 & 0 & 0 & 0 \\
\hline & 3 & 31 & 22 & 71 & 8 & 26 & 1 & 3 & 0 & 0 & 0 & 0 \\
\hline & Average & 24.67 & 19 & 78.1 & 5.33 & 20.9 & 0.33 & 1 & 0 & 0 & 0 & 0 \\
\hline \multirow[t]{4}{*}{ Low } & 1 & 25 & 19 & 76 & 6 & 24 & 0 & 0 & 0 & 0 & 0 & 0 \\
\hline & 2 & 16 & 12 & 75 & 4 & 25 & 0 & 0 & 0 & 0 & 0 & 0 \\
\hline & 3 & 32 & 28 & 88 & 4 & 13 & 0 & 0 & 0 & 0 & 0 & 0 \\
\hline & Average & 24.33 & 19.67 & 79.67 & 4.67 & 20.67 & 0 & 0 & 0 & 0 & 0 & 0 \\
\hline
\end{tabular}

The researcher believes that one of the reasons for the low percentages of the inference sublevels (analysis, composition, evaluation) is that the textbook in the first place does not pay more attention to it. This is further confirmed by the findings of Sprague (2008), who called for more representations of the sublevels in the maths textbook, which in turn would encourage teachers to include them in their exams.

Finally, the findings of this study indicate that the tools used by teachers and in the textbook are weak in terms of including thinking levels, and the researcher of this study believes that after assessing the maths textbook, teachers' exams and teachers' classroom discussion, this may influence the development of high-level students' thinking level.

There are variations in the teachers' performance levels in this area between one school and another, and the excellence the students show in the thinking levels aspect from school to school. Nevertheless, there is a gap between the theories and orientations toward upgrading the thinking level among students, on the one hand, and the real practices represented in curriculum design, test preparation and the current teachinglearning practices in the schools, on the other. 


\section{CONCLUSION AND RECOMMENDATIONS}

The findings of this study indicate that the tools used by teachers and in the textbook are weak in terms of including thinking levels. This study is just an attempt to direct the attention of the decision-makers among educators toward the need to reconsider the contents of the elementary eighth -grade maths curriculum. The researcher strongly recommends that they include situations that require the employment of higher thinking levels. In this regard, a curriculum based on a flexible structure provides wide-ranging opportunities for both teachers and students to navigate in a joint learning process, through a mutual dialogue, which depends on initiation, thinking and deliberation. However, as long as the exams are founded on accumulative information examinations, which are based on "one correct answer" (we learn and study what we will be examined in, and we take exams in what we have studied), there is no way we can talk about scalable, life-linked thinking levels, no matter how flexible the curriculum is. Furthermore, the change in the style of examinations necessitates changing the classroom interaction patterns, creating an area for discussion, raising questions, making comments on thoughts and expressing views. Consequently, it is essential to unfold the teaching evaluation file, to explore methods to assess these thoughts, views and comments, in a manner that goes beyond the way in which the one correct answer is assessed.

We also have to look into the background of the teacher in terms of thinking levels, the teaching philosophy they adopt and the level of expectations of their students. This is vitally important if we wish to achieve effective participation in the classroom, and move from teacher-based teaching to student-based teaching. There is a need to focus on employing thinking levels in teaching practices, and increasing cooperation between both high- and low-performance schools, with a view to exchanging the teaching experience and best successes in any of these schools.

\section{REFERENCES}

Akyuzi, G. (2014). The Effects of Student and School Factors on Mathematics Achievement in TIMSS 2011. Education and Science, 39, 172, 150-162.

AL-Habeeb, M. (2014). Assessment of the fourth elementary grade math textbook in Kingdom of Saudi Arabic, as per the (TIMSS, 2011) requirements (Unpublished MA Thesis). Al-Qaseem University, Saudi Arabia.

Al-Hamami, E. (2015). Assessment of the contents of the Palestinian math books for the grades (5-8) in the light of TIMSS standard. (Unpublished MA Thesis). Al-Azhar University, Gaza.

Al-Hayyari, E. (2002). Use of Kumar's System for analyzing the classroom interaction of the male and female physics teachers, and its influence in gaining the scientific skills of the fifth scientific grade (Diploma Research), Al-Mousul University, Iraq.

Al-Mukhtar, R. (2005). Patterns of classroom interactions of the male and female math teachers and their mathematical thinking, achievement and trends toward math with the 
preparatory stage students (Unpublished Ph.D. Dissertation). Al-Mousul University, Iraq.

Al-Taleeni, I. (2013). Assessment of the fourth elementary grade math textbook in Palestine based on (TIMSS) requirements (Unpublished MA Thesis). The Islamic University, Gaza.

Anderson, L., \& Krathwohl, D. (Eds.). (2001). A taxonomy for learning, teaching, and assessing: A revision of Bloom's taxonomy of educational objectives. New York: Longman.

Asuman, D., \& Oylum, A. (2007). An Observation Study in Elementary Mathematics Classrooms. Education and Science, 32(145), 16-22.

Barak, M., \& Shakhman, L. (2008). Fostering Higher-Order Thinking in Science Class: Teachers' Reflections. Teachers and Teaching: Theory and Practice, 14,/3, 191-208. doi: 10.1080/13540600802006079

Bloom, B., Engelhart, M., Furst, E., Hill, W., \& Krathwohl, D. (1956). Taxonomy of educational objectives: The classification of educational goals. Handbook I: Cognitive domain. New York, Toronto: Longmans Green.

Bufford, K. (2011). Elementary pre-service teachers' conceptions of common approaches to teaching science and mathematics (Unpublished Ph.D. Dissertation). Auburn University: Alabama.

Carla, J., \& Sandra, B. (2014), Classroom Observation Data and Instruction in Primary Mathematics Education: Improving Design and Rigor, Mathematics Education Research Journal, 26,301-323. doi:10.1007/s13394-013-0099-y

Cathcart, G., Pothier, Y., Vance, J., \& Bezuk, N. (2011). Learning mathematics in elementary and middle schools: A learner-centered approach. (5th edn.) USA:Pearson Education Inc

Clark, D. (2010). Bloom's taxonomy of learning domains: The three types of learning. In: W.A. Edmonds (Ed.), Big dog \& little dog's performance juxtaposition. Retrieved [22/4/2017] from http://www.nwlink.com/ donclark/hrd/bloom.html

Evnitskaya, N., \& Morton, T. (2011). Knowledge Construction, Meaning-making and Interaction in CLIL Science Classroom Communities of Practice. Language and Education, 25,2, 109-127. doi 10.1080/09500782.2010.547199

Gencal, I. (2017). The effect of portfolio assessments on metacognitive skills and on attitudes toward a course. Educational Sciences: Theory \& Practice, 17(1), 293-319. doi: 10.12738/estp.2017.1.0378

Gruber, S., \& Boreen, J. (2003). Teaching critical thinking using experience to promote learning in middle school and college students. Teachers and Teaching: Theory and Practice, 9(1), 5-19. doi: 10.1080/1354060032000049878

Harrigan, A. \& Vincenti, V. (2004). Developing Higher-Order Thinking through an 
Intercultural Assignment: A Scholarship of Teaching Inquiry Project, College Teaching, $52,3,113-121$.

Inamullah, H., Hussain, I., \& Ud Din, M. (2008). Teacher-Students Verbal Interaction at the Secondary Level. Journal of College Teaching \& Learning, 5(9), 41-43.

Kawulich, B. (2005). Participant Observation as a Data Collection Method. Forum Qualitative Sozialforschung/Forum: Qualitative Social Research, 6(2), 1-39. doi: $10.17169 /$ fqs-6.2.466

Kilday, R. (2010). Factors affecting children's math achievement scores in preschool (Unpublished Ph.D. Dissertation). University of Virginia: USA.

Kim, H., Sefcik, J., \& Bradway, C. (2017). Characteristics of Qualitative Descriptive Studies: A Systematic Review. Research in Nursing \& Health, 40(1), 23-42. soi: 10.1002/nur.21768

Krathwohl, D. (2002). A revision of Bloom's Taxonomy: An Overview. Theory into Practice, 41(4), 212-218. doi: 10.1207/s15430421tip4104_2

Lemke, J. (1990). Talking science: Language, learning, and values. Norwood, NJ: Albex Publishing.

Little, E. (2009). Teaching mathematics: Issues and solutions. Teaching exceptional children plus. Retrieved [2/5/2017] from: http://scholarship.bc.edu/education/tecplus/vol6/iss1/art1

Martin, M., Mullis, I., Foy, P., \& Stanco, G. (2012). TIMSS 2011 international results in science. Chestnut Hill, MA: TIMSS \& PIRLS International Study Center, Boston College.

Mullis, I. \& Martin, M. (2015). TIMSS 2015 assessment frameworks. United States: International Association for Evaluation of Education Achievement.

National Center for Human Resources Development. (2017). Jordanian national report of TIMSS 2015 study. The Center Publications Series 170. Amman, Jordan.

Rashid, S., \& Qaisar, S. (2016). Developing Critical Thinking through Questioning Strategy among Fourth Grade Students. Bulletin of Education and Research, 38(2), $153-168$.

Sinclair, J., \& Coulthard, M. (1975). Towards an analysis of discourse. Oxford: Oxford University Press.

Sprague, R. (2008). A correlational study of California high school mathematics teacher qualifications and student performance (Unpublished Ph.D. Dissertation). Walden University.

Sulkua, S., \& Abdioglub, Z. (2015). Public and Private School Distinction, Regional Development Differences, and Other Factors Influencing the Success of Primary School Students in Turkey. Educational Sciences: Theory \& Practice, 15 (2), 419-431. doi: 


\subsection{8/estp.2015.2.2386}

Wallace, M. (2011). Developing assessment practices: A study of the experiences of pre-service mathematics teachers as learners and the evolution of their assessment practices as educators (Unpublished Ph.D. Dissertation). University of California.

Wells, G. (1999). Language as Education: Reconceptualising Education as Dialogue. Annual Review of Linguistics, 19, 135-155. 